\title{
A CASE-CONTROL STUDY OF MULTIPLE MYELOMA NESTED IN THE AMERICAN CANCER SOCIETY PROSPECTIVE STUDY
}

\author{
P. BofFetTA ${ }^{1,2,3}$, S.D. STELlmaN ${ }^{1}$ and L. GARFINKEL ${ }^{1}$ \\ 'Department of Epidemiology and Statistics, American Cancer Society, 1180 Avenue of the Americas, New York, NY 10036, USA; \\ and ${ }^{2}$ Dipartimento di Scienze Biomediche e Oncologia Umana, Cattedra di Epidemiologia dei Tumori, Università di Torino, via \\ Santena 7, 10126 Turin, Italy.
}

\begin{abstract}
Among the subjects enrolled in the American Cancer Society Cancer Prevention Study II, a large nation-wide prospective study, 282 died from multiple myeloma (MM) during the first 4 years of follow-up. These were divided into incident cases who were initially free from disease and prevalent cases who reported MM or related symptoms at the time of enrollment. For each case, 4 controls matched for age, sex, ethnic group and residence were randomly selected. Previous history of diabetes [odds ratio $(O R)=2.0$ ] and employment as farmer $(O R=2.7)$ were the risk factors consistently suggested by the results of the analysis. The risk associated with farming showed a linear trend with duration of exposure. Pesticide or herbicide exposure was not a risk factor per se but, when combined with farming, it increased the OR to 4.3. Low education, occupational exposure to dyes, and employment in a bank, on the railroad or as a maid were also suggested risk factors, but either they were not statistically significant or they were based on small numbers of exposed subjects. No association between MM and asbestos exposure was observed.
\end{abstract}

Multiple myeloma (MM) is a malignant neoplasm of plasma cells, usually generalized, mainly involving bone, bone marrow and kidney. It results from an unbalanced proliferation of a clone of B-lymphocyte-derived cells, that normally synthesize and secrete immunoglobins.

An estimated 8,200 Americans will have died of MM in 1988 (ACS, 1988); the survival experience is quite poor: median survival time ranges between 24 and 45 months, depending on tumor mass (McIntyre, 1985).

$\mathrm{MM}$ is more frequent in the elderly, and among men and Blacks (Pottern and Blattner, 1985), and is among the few cancers whose mortality rates have steadily increased over recent decades (Devesa et al., 1987). Several epidemiological studies on the etiology of MM have recently been published. They investigated the role of environmental and occupational exposures - mainly radiation, paper and wood industry, farming, petroleum industry - as well as familial and genetic factors. Two reviews of these studies have also been published (Blattner, 1982; Pottern and Blattner, 1985). Results presented here are based on a case-control analysis nested in a nationwide, on-going, prospective mortality study.

\section{MATERIAL AND METHODS}

In 1982, more than 77,000 American Cancer Society (ACS) volunteers enrolled over 1.2 million men and women in a prospective mortality study, Cancer Prevention Study II (CPSII). Those enrolled, who were usually friends, neighbors, or relatives of the volunteers, compiled a 4-page confidential questionnaire on history of cancer and other diseases; occupational history and exposures; current and past use of medicines and vitamins; menstrual and reproductive history; current diet; history of drinking, smoking and numerous other habits. Enrollment was by family groups with at least one person aged 45 or more, and all members of the household over 30 years of age were asked to participate.

Enrollment of subjects was carried out in all 50 of the United
States, the District of Columbia and Puerto Rico. Every second year, volunteers are asked to check if the enrollees are alive or dead, and to record date and place of death. Death certificates were subsequently obtained through State health departments. The first 2 follow-ups took place in 1984 and 1986.

Three questions on occupation were asked: current job, last occupation if retired, and any other job held for the longest period of time. Occupations were coded using an ad-hoc system with 65 different categories. A more specific classification, such as a 3-digit Standard Industrial Classification code, was impractical for the large number of ambiguous responses derived from a self-administered questionnaire.

Every subject was classified according to reported employment in any period of life ("ever employed"), as well as according to "usual" occupation. The latter was obtained either from current job, if held for 10 or more years, or from the remaining information.

Exposure in the workplace or in the daily life to any of 12 groups of substances (asbestos, chemicals/acids/solvents, coal or stone dusts, coal tar/pitch/asphalt, diesel engine exhaust, dyes, formaldehyde, gasoline exhaust, pesticides/herbicides, textile fibers/dusts, wood dust, X-rays/radioactive materials) was investigated in the following section of the questionnaire. The duration of every employment and exposure was also asked.

Causes of death were derived from death certificates and coded by a trained nosologist according to the International Classification of Diseases, 9th Revision.

The present analysis is based on 508,637 men and 676,613 women who provided usable questionnaires. Four-year mortality experience was available for 48 out of 58 ACS divisions in which the study is organized (divisions correspond to States or to some large metropolitan areas), while 10 divisions had data for 2 years only.

Subjects who had died, with MM reported on death certificate as either the underlying or contributing cause of death, formed the case series; 4 randomly selected subjects were matched to each case for sex, ACS division, year of birth and ethnic group, to form the control group.

The incident nature of the cases was ascertained through a manual check of the questionnaires in which any information about prior or present cancer was reported; selected cases were therefore divided into "incident" and "prevalent" cases, and were analyzed separately. Data from prevalent cases, whose recall of past exposures may be biased by knowledge of disease status, and whose current habits and conditions may reflect the disease itself, were analyzed in order to confirm or disprove results from incident cases.

A 3-step procedure of analysis was used: crude unmatched odds ratios (OR), Mantel-Haenszel matched OR (Mantel and Haenszel, 1959), and conditional logistic regression (Breslow

${ }^{3}$ To whom reprint requests should be sent, at the University of Turin.

Received: July 4, 1988 and in revised form November 3, 1988. 
and Day, 1980). In order to control for potential confounding factors other than matching variables (education, history of diabetes, X-ray treatment, farming, pesticide and herbicide exposure), the regression was carried out using the PECAN program (Lubin, 1981). Test-based $95 \%$ confidence intervals (CI) were calculated according to Miettinen (1976). Linear trends were tested according to Mantel (1963). The MannWhitney test was used to test differences between distributions. Adjusted population attributable risks were calculated using logistic regression coefficients (Bruzzi et al., 1985).

\section{RESULTS}

After 4 years of follow-up, $98.5 \%$ of subjects were traced, and death certificates were obtained for about $84 \%$ of deceased subjects when this analysis was started. At the 2-year followup, $99.2 \%$ of subjects were traced and $96.8 \%$ of death certificates were obtained. In order to assess the quality of death certificate coding, about $25 \%$ of cases' death certificates were manually checked, and no errors were detected. A further check of selected items from about $10 \%$ of cases' and controls' questionnaires showed a very low data entry error rate for most variables, with the exception of the information on previous cancer: this variable was manually checked for all subjects.

MM was mentioned on the death certificates of 282 subjects. Nine of these did not have 4 controls satisfying all matching criteria: therefore 8 were matched within 2 years of age, and 1 within 5 years. The number of MM cases on which this analysis is based (282) is slightly higher than the number of expected deaths according to 1984 age, sex and ethnic groupspecific US death rates (261), but only 249 cases had MM as the underlying cause of death, the information on which national mortality statistics are based. Of the cases, 149 reported a previous or current history of MM, and 5 more subjects stated symptoms which can be related to MM, without mentioning the disease. These were all combined as "prevalent" cases. The remaining 128 cases, with no mention of MM or related symptoms, were considered to be "incident" cases. Unless otherwise specified, all results reported below refer to incident cases.

The numbers of incident and prevalent cases and controls by sex, ethnic group, age and year of death are shown in Table I.
As may be expected, prevalent cases tended to die earlier than incident cases.

Forty-nine variables were used to investigate factors other than occupation. Table II shows those associated with an increased risk in this analysis or in previous studies.

Low education was significantly associated with MM; subjects without a high school degree had an OR $=1.5$ compared with subjects with such a degree. Previous history of 8 nonmalignant conditions (diabetes, kidney disease, chronic bronchitis, stomach ulcer, tuberculosis, hay fever, asthma, and arthritis) was analyzed. Only diabetes showed a significant association with MM, a finding that was confirmed among prevalent cases $(\mathrm{OR}=1.8,95 \% \mathrm{CI}: 1.0-3.2)$. Kidney disease was strongly associated with $\mathrm{MM}$ among prevalent cases $(\mathrm{OR}=3.4,95 \% \mathrm{CI}: 1.3-8.8)$, but not among incident cases.

No association was observed with current or former cigarette, cigar, pipe, or total tobacco smoking, nor with consumption of milk, caffeinated or decaffeinated coffee, tea, diet or non-diet sodas, beer, wine, hard liquors or total alcohol. Significantly more cases than controls reported a private well as the source of drinking water, while no difference in the consumption of food rich in protein or animal fat, of fried foods, fruits and vegetables or artificial sweeteners was observed.

No significant difference in the history of X-ray examinations or X-ray treatment was observed among incident cases and controls, while both exposures were strongly associated with $\mathrm{MM}$ among prevalent cases: $\mathrm{OR}=4.0$ (95\% CI: 2.6 5.9) and $\mathrm{OR}=5.9(95 \% \mathrm{CI}: 4.0-8.8)$, respectively.

No excess risk was found according to marital status, religion, or indicators of social activity (number of friends to whom the subject was feeling close, church or temple attendance, participation in group or club activities). Moreover, no difference was found in subjects' or parents' place of birth: specifically, 5 cases and 20 controls either were born or had parents who were born in Nordic countries $(\mathrm{OR}=1.0)$. No association was found for weight, change of weight in the year prior to enrollment, height, history of operations, or family history of cancer: specifically, the number of reported MM cases among parents and siblings was 0 out of 605 relatives for incident cases, 2/2,435 for their controls, 2/765 for prevalent cases, and $0 / 2,919$ for their controls.
TABLE I - SUBJECTS ENROLLED IN THE ANALYSIS BY SEX, ETHNIC GROUP, AGE, YEAR OF DEATH, AND INCIDENT NATURE OF THE DISEASE

\begin{tabular}{|c|c|c|c|c|}
\hline & \multicolumn{2}{|c|}{ Incident } & \multicolumn{2}{|c|}{ Prevalent } \\
\hline & $\overline{\text { Cases }}$ & Controls & Cases & Controls \\
\hline \multicolumn{5}{|l|}{ Sex } \\
\hline Male & 74 & 296 & 83 & 332 \\
\hline Female & 54 & 216 & 71 & 284 \\
\hline \multicolumn{5}{|c|}{ Ethnic group } \\
\hline White & 116 & 464 & 143 & 572 \\
\hline Black & 9 & 36 & 7 & 28 \\
\hline Other & 3 & 12 & 4 & 16 \\
\hline \multicolumn{5}{|l|}{ Age } \\
\hline $30-54$ & 14 & 56 & 12 & 48 \\
\hline $55-64$ & 29 & 114 & 61 & 245 \\
\hline $65-74$ & 59 & 238 & 49 & 195 \\
\hline $75+$ & 26 & 104 & 32 & 128 \\
\hline \multicolumn{5}{|c|}{ Year of death } \\
\hline 1982 & 4 & & 21 & \\
\hline 1983 & 24 & & 61 & \\
\hline 1984 & 40 & $\mathrm{NA}^{1}$ & 37 & NA \\
\hline 1985 & 28 & & 21 & \\
\hline 1986 & 32 & & 14 & \\
\hline Total & 128 & 512 & 154 & 616 \\
\hline
\end{tabular}

${ }^{1}$ Not applicable.
TABLE II - MULTIPLE MYELOMA RISK AND EXPOSURES OTHER THAN OCCUPATION; INCIDENT CASES

\begin{tabular}{|c|c|c|c|}
\hline Exposure & $\mathrm{Ca} / \mathrm{Co}^{1}$ & $\mathrm{OR}^{2}$ & $95 \% \mathrm{CI}^{3}$ \\
\hline Education $^{4}$ & $45 / 137$ & 1.5 & $1.0-2.3$ \\
\hline History of disease ${ }^{5}$ : hay fever & $14 / 38$ & 1.6 & $0.8-2.9$ \\
\hline asthma & $5 / 21$ & 1.0 & $0.3-2.7$ \\
\hline arthritis & $39 / 164$ & 0.9 & $0.6-1.5$ \\
\hline diabetes & $17 / 38$ & 1.9 & $1.1-3.4$ \\
\hline kidney dis. & $5 / 14$ & 1.4 & $0.5-4.0$ \\
\hline Tobacco smoking6 & $69 / 289$ & 0.9 & $0.6-1.3$ \\
\hline Alcohol drinking ${ }^{7}$ & $20 / 133$ & 0.5 & $0.3-0.9$ \\
\hline Drinking water supply ${ }^{8}$ & $31 / 80$ & 1.7 & $1.1-2.7$ \\
\hline Dietary habits ${ }^{9}$ animal fat & $59 / 242$ & 1.0 & $0.6-1.4$ \\
\hline fried foods & $43 / 176$ & 1.0 & $0.6-1.5$ \\
\hline fruits-veg. & $63 / 225$ & 1.2 & $0.8-1.8$ \\
\hline$X$-ray treatment ${ }^{10}$ & $14 / 40$ & 1.4 & $0.8-2.6$ \\
\hline $\mathrm{X}$-ray examinations ${ }^{11}$ & $62 / 259$ & 0.9 & $0.6-1.4$ \\
\hline
\end{tabular}

${ }^{1}$ Exposed cases and controls.- ${ }^{2}$ Mantel-Haenszel matched odds ratio.- ${ }^{395} \%$ confidence interval. $-{ }^{4}$ Exposed: less than high-school grade. Not exposed: high-school grade or higher. $-^{5}$ Exposed: positive history. Not exposed: no history.- ${ }^{6}$ Exposed: grade or higher.- ${ }^{5}$ Exposed: positive history. Not exposed: no history.-'Exposed: posed: never regular drinker.- ${ }^{8}$ Exposed: private well. Not exposed: public water supply or other. $-{ }^{9}$ Exposed: consumption (days/week) of foods above the median of the consumption of combined cases and controls. Not exposed: consumption below the median. Animal fat: meat, sausages, cheese, butter, eggs.- ${ }^{10}$ Exposed: positive history of treatment. Not exposed: no history of treatment.- ${ }^{11}$ Exposed: number of $\mathrm{X}$-ray examinations above the median of the number of examinations of combined cases and controls. Not exposed: total number below the median. 
Among women, no significant difference was found according to use of hair dyes, oral contraceptives, or exogenous estrogens, or according to menopausal status and difficulty in conceiving.

Table III shows the association between MM and 12 occupational exposures. Self-reported exposure to pesticides or herbicides was just significantly associated with MM $(p=0.05)$, and a non-significant increase was also present for exposure to textile fibers and dusts, wood dust, X-rays and radioactive materials, and dyes. The absence of an association with asbestos was confirmed for prevalent cases $(\mathrm{OR}=1.3,95 \% \mathrm{CI}$ : $0.6-2.9)$. The risk for exposure to pesticides or herbicides was higher among prevalent than among incident cases $(\mathrm{OR}=3.4,95 \%$ CI: $1.8-6.3,19$ exposed cases $)$.

Among 16 occupations with at least 2 exposed cases and 2 exposed controls (Table IV), farming had an OR of 3.4 (95\% CI: 1.5-7.5). Other occupations showed an increase in risk, based on a few cases and controls: maid, bank worker and railroad worker $(p<0.05)$, truck driver and janitor $(p>$ 0.05 ). Among prevalent cases and their controls, there were $13 / 27$ farmers $(\mathrm{OR}=2.5, p<0.05), 0 / 4$ bank employees, $1 / 8$ truck drivers, $0 / 2$ railroad workers, and $2 / 3$ janitors $(\mathrm{OR}=2.7, p>0.05)$. One incident case and 3 controls were assemblers, as were 3 prevalent cases and 2 controls (OR for prevalent cases $=6.0, p<0.05$ ). When this analysis was repeated, classifying subjects in every occupation that was reported in the occupational history ("ever employed"), only minor changes in the results were detected.

The relationship between farming and MM was specifically addressed by several further analyses. If incident and prevalent cases are combined, the OR for farmers is 2.9 (95\% CI: 1.75.1); 18 incident cases and 38 controls were "ever employed", as farmers $(\mathrm{OR}=2.7,95 \% \mathrm{CI}: 1.3-5.7)$.

Table $\mathrm{V}$ shows the association between farming and $\mathrm{MM}$ among incident cases, by duration of farming and birth cohort. It was not possible to determine the duration of exposure for $8 / 16$ exposed cases, and 11/28 controls; a trend in risk with increasing duration is nevertheless suggested. When farmers are analyzed by birth cohort, an increase in risk is present only among subjects born before 1920 . Given the small number of subjects, it was impossible to separate the effects of age and duration of exposure: they may merely reflect a higher risk in older persons. The relationship between farming, exposure to pesticides or herbicides, and MM risk is shown in Table VI.

TABLE III - MULTIPLE MYELOMA RISK AND OCCUPATIONAL EXPOSURES; INCIDENT CASES

\begin{tabular}{|c|c|c|c|}
\hline Exposure & $\mathrm{Ca} / \mathrm{Co}^{1}$ & $\mathrm{OR}^{2}$ & $95 \% \mathrm{CI}^{3}$ \\
\hline $\begin{array}{l}\text { Pesticides and } \\
\text { herbicides }\end{array}$ & $12 / 25$ & 2.1 & $1.0-4.2$ \\
\hline Asbestos & $3 / 17$ & 0.7 & $0.2-2.4$ \\
\hline Diesel exhaust & $14 / 43$ & 1.4 & $0.7-2.7$ \\
\hline $\begin{array}{l}\text { Textile fibers } \\
\text { and dusts }\end{array}$ & $8 / 19$ & 1.8 & $0.8-4.4$ \\
\hline Wood dust & $9 / 23$ & 1.8 & $0.7-4.3$ \\
\hline $\begin{array}{l}\mathrm{X} \text {-rays, radioactive } \\
\text { material }\end{array}$ & $7 / 15$ & 1.9 & $0.8-4.8$ \\
\hline $\begin{array}{l}\text { Chemicals, acids, } \\
\text { solvents }\end{array}$ & $8 / 58$ & 0.5 & $0.2-1.1$ \\
\hline Coal or stone dusts & $6 / 24$ & 1.0 & - \\
\hline $\begin{array}{l}\text { Coal tar, pitch, } \\
\text { asphalt }\end{array}$ & $4 / 10$ & 1.7 & $0.5-5.6$ \\
\hline Dyes & $5 / 8$ & 2.7 & $0.9-8.6$ \\
\hline Formaldehyde & $4 / 9$ & 1.8 & $0.6-5.7$ \\
\hline Gasoline exhaust & $14 / 64$ & 0.9 & $0.5-1.6$ \\
\hline
\end{tabular}

${ }^{1}$ Exposed cases and controls.- ${ }^{2}$ Mantel-Haenszel matched odds ratio.-- ${ }^{395 \%}$ confidence interval. TABLE IV - MULTIPLE MYELOMA RISK AND OCCUPATION; INCIDENT

\begin{tabular}{lccc}
\hline \multicolumn{1}{c}{ Occupation } & & & \\
\cline { 1 - 2 } Teacher & $\mathrm{Ca} / \mathrm{Co}^{2}$ & $\mathrm{OR}^{3}$ & $95 \% \mathrm{CI}^{4}$ \\
Manager & $10 / 59$ & 0.6 & $0.3-1.3$ \\
Office worker & $6 / 51$ & 0.5 & $0.2-1.1$ \\
Bookkeeper & $14 / 45$ & 1.3 & $0.7-2.7$ \\
Bank employee & $3 / 16$ & 0.8 & $0.2-2.5$ \\
Real estate agent & $5 / 4$ & 5.0 & $1.5-16.3$ \\
Registered nurse & $3 / 8$ & 1.5 & $0.4-5.4$ \\
Sales worker & $2 / 10$ & 0.8 & $0.2-3.6$ \\
Pharmacist & $12 / 47$ & 1.0 & $0.5-2.0$ \\
Auto mechanic & $2 / 5$ & 1.6 & $0.3-8.1$ \\
Truck driver & $3 / 13$ & 0.9 & $0.2-3.5$ \\
Railroad worker & $3 / 3$ & 4.0 & $0.9-17.6$ \\
Farmer & $3 / 2$ & 6.0 & $1.3-28.9$ \\
Janitor & $16 / 28$ & 3.4 & $1.5-7.5$ \\
Maid & $4 / 6$ & 2.7 & $0.8-9.0$ \\
Food worker & $4 / 4$ & 5.0 & $1.2-21.1$ \\
\hline
\end{tabular}

${ }^{1}$ Main occupation during life (see text for details). Not exposed: for any occupation, all other subjects. Only occupations with at least 2 exposed cases and controls are listed separately. $-{ }^{2}$ Exposed cases and controls. $-{ }^{3}$ Mantel-Haenszel matched odds ratio. $-495 \%$ confidence interval.

An association with pesticide and herbicide exposure is suggested among farmers, but not among non-farmers.

In Table VII, results from a conditional logistic regression analysis on selected risk factors are reported. After controlling for possible confounders, the ORs for level of education, drinking water supply, and occupational exposure to pesticides or herbicides, textile fibers, wood dust and X-rays were lowered; therefore these associations appear to be confounded by the factors controlled for, namely employment as farmers, while the ORs for previous history of diabetes, exposure to dyes, farming and other high-risk occupations were not substantially modified.

\section{DISCUSSION}

Follow-ups in CPSII are carried out very carefully: the proportions of subjects who were traced and for whom death certificates were obtained are among the highest ever reported in large prospective studies.

Questionnaires were filled out by sứbjects themselves, data were entered by specialized personnel, and causes of death were coded from death certificates by a trained nosologist; several manual checks showed that the overall quality of data is high.

Characterization of cases as incident or prevalent was an important step in this analysis, since subjects diseased at enrollment might recall exposure history in a different way from subjects free from disease. When results from incident and prevalent cases are compared, however, it seems that major findings of this analysis are consistently present in both groups, and that discrepancies in the results reflect actual differences between the 2 groups. Prevalent cases were more likely to report a history of kidney disease, which is a major clinical manifestation of MM. They were also more likely to have undergone multiple X-ray examinations and X-ray treatment, as is expected with MM patients.

This analysis did not confirm the association between chronic immunologic disorders, such as rheumatoid arthritis and asthma, and MM, that was suggested by some case reports (Imahori and Moore, 1972) and epidemiological studies (Isomaki et al., 1978; Hakulinen et al., 1985), but not confirmed by another study (Linet et al., 1987). Only a generic definition of "arthritis" was available from the questionnaire. No information was available from this study in order to test the hy- 
TABLE V - MULTIPLE MYELOMA RISK AND FARMING. EFFECT OF DURATION OF EXPOSURE AND YEAR OF BIRTH; INCIDENT CASES

\begin{tabular}{|c|c|c|c|c|c|}
\hline & & & $\mathrm{Ca} / \mathrm{Co}^{1}$ & $\mathrm{OR}^{2}$ & $95 \% \mathrm{CI}^{3}$ \\
\hline \multirow[t]{5}{*}{ Duration $^{5}$} & & Not exposed ${ }^{4}$ & $112 / 484$ & 1.0 & - \\
\hline & & $1-20$ years & $0 / 6$ & - & - \\
\hline & & $21-40$ years & $2 / 5$ & 1.7 & $0.3-8.9$ \\
\hline & & $41+$ years & $6 / 6$ & 4.3 & $1.5-12.5$ \\
\hline & & Missing duration & $8 / 11$ & 3.1 & $1.3-7.7$ \\
\hline \multirow[t]{6}{*}{ Year of birth } & $<1910$ & Not exposed 4 & $34 / 154$ & 1.0 & - \\
\hline & & Exposed & $7 / 10$ & 3.2 & $1.2-8.6$ \\
\hline & 1910-1919 & Not exposed 4 & $43 / 188$ & 1.0 & - \\
\hline & & Exposed & $8 / 13$ & 2.7 & $1.1-6.7$ \\
\hline & $>1919$ & Not exposed 4 & $35 / 142$ & 1.0 & - \\
\hline & & Exposed & $1 / 5$ & 0.8 & $0.1-7.2$ \\
\hline
\end{tabular}

${ }^{1}$ Cases and controls. $-{ }^{2}$ Mantel-Haenszel matched odds ratio.- ${ }^{395 \%}$ confidence interval.- ${ }^{4}$ Reference category.- ${ }^{5}$ Test for linear trend: $p$-value $<0.05$.

pothesis, derived from case reports, of a role of vaccinations (Woodroffe, 1972), or sarcoidosis (Petterson et al., 1987) in the etiology of MM.

The association between MM and previous history of diabetes has not been previously reported; in fact, Gallagher et al. (1983) reported a negative association. The present result may be due to chance only. The increase is consistent among both incident and prevalent cases, and the prevalence of history of diabetes is not lower among controls than in the entire CPSII cohort. However, results from other studies are needed before one can speculate about a possible biological interpretation of this result, which may be related to a general alteration of the immune system.

No association was found between $\mathrm{MM}$ and origin from Nordic countries, as suggested by an ecological study (Blattner et al., 1981), but not confirmed by an analytical study (Nandakumar et al., 1986), nor was the suggestion of familial clustering of MM, derived from case reports (Kyle and Greipp, 1983) and one case-control study (Bourguet et al., 1985), confirmed by the present analysis.

Subjects who had not attained high-school education were at higher risk of MM in comparison with subjects having received higher education, but the difference was not statistically significant. No association with education was found in 2 studies (Johnston et al., 1985; Nandakumar et al., 1986), while an increase of MM risk among subjects from lower social or economic class has been reported (Pearce et al., 1985; Nandakumar et al., 1986). It is likely that education level is a proxy variable for environmental or occupational factors other than those analyzed.

The lack of an association between MM and life-style factors such as smoking, drinking and diet confirms the findings from previous studies (Gallagher et al., 1983; Linet et al., 1987; Flodin et al., 1987).

Farming was suggested as a risk factor for MM from ecological (Agu et al., 1980; Blattner et al., 1981) and analytical

TABLE VI - MULTIPLE MYELOMA RISK, FARMING, AND PESTICIDE AND HERBICIDE EXPOSURE; INCIDENT CASES

\begin{tabular}{llcc}
\hline & HERBICIDE EXPOSURE; INCIDENT CASES & \\
\hline Non-farmers & $\begin{array}{c}\text { Unexposed to } \\
\text { pesticides } \\
\text { and herbicides }\end{array}$ & $\begin{array}{c}\text { Exposed to } \\
\text { pesticides } \\
\text { and herbicides }\end{array}$ \\
\hline \multirow{5}{*}{ Farmers } & Cases/controls & $108 / 467$ & $4 / 17$ \\
& OR $^{1}$ & $1.0^{2}$ & 1.0 \\
& $95 \%$ CI $^{3}$ & - & $0.3-3.1$ \\
& Cases/controls & $8 / 20$ & $8 / 8$ \\
& OR & 1.7 & 4.3 \\
& $95 \% \mathrm{CI}^{3}$ & $0.8-4.0$ & $1.7-10.9$ \\
\hline
\end{tabular}

${ }^{1}$ Unmatched odds ratio.-2Reference category.-395\% confidence interval. epidemiological studies (Milham, 1971; Gallagher et al., 1983; Burmeister et al., 1983; Cantor and Blair, 1984; Pearce et al., 1985; Delzell and Grufferman, 1985; Steineck and Wiklund, 1986; Nandakumar et al., 1986; Flodin et al., 1987; McLaughlin et al., 1988; Cuzick and De Stavola, 1988). Three other studies, however, did not confirm this finding (Tollerud et al., 1985; Linet et al., 1987; Brownson and Reif, 1988). This association is strongly confirmed by the present analysis for subjects born before 1920; it is present for both incident and prevalent cases, and there is a trend toward increasing risk with duration of exposure.

Two different hypotheses have been proposed in order to identify a specific etiologic agent: exposure to chemicals, such as pesticides, insecticides and herbicides (Burmeister et al., 1983; Cantor and Blair, 1984; Morris et al., 1986; Flodin et al., 1987), and exposure to some viruses (Priester and Mason, 1974). Both explanations have some biological plausibility, given the known carcinogenic effect of organic chemicals, such as benzene, on hematopoietic cells, the experimental carcinogenicity of several pesticides and herbicides, including DDT, and the suggestion of a carcinogenic effect of phenoxy herbicides on soft tissues (IARC, 1988).

The evidence of viral myeloma-related diseases in animals (Sharma et al., 1973), and of horizontal transmission of their

TABLE VII - MULTIPLE MYELOMA RISK AND SELECTED RISK FACTORS RESULTS OF LOGISTIC REGRESSION ANALYSIS ${ }^{1}$; INCIDENT CASES

\begin{tabular}{lcc}
\hline \multicolumn{1}{c}{ Risk factor $^{2}$} & Odds ratio & $95 \% \mathrm{Cl}^{3}$ \\
\hline Education & 1.4 & $0.9-2.2$ \\
Previous history of diabetes & 2.0 & $1.1-3.8$ \\
Tobacco smoking & 0.9 & $0.6-1.4$ \\
Alcohol drinking & 0.6 & $0.3-1.0$ \\
Drinking water supply & 1.3 & $0.8-2.2$ \\
Fruits and vegetables in diet & 1.2 & $0.8-1.8$ \\
X-ray treatment & 1.6 & $0.8-3.0$ \\
Occupational exposure to: & & \\
pesticides/herbicides & 1.6 & $0.7-3.7$ \\
textile fibers/dusts & 1.2 & $0.4-3.3$ \\
wood dust & 1.2 & $0.5-3.2$ \\
X-rays, radioactive mat. & 1.4 & $0.5-3.9$ \\
dyes & 2.9 & $0.8-10.3$ \\
truck driver & 2.7 & $1.3-5.7$ \\
janitor & 2.8 & $0.5-16.1$ \\
bank employee & 2.3 & $0.6-8.5$ \\
maid & 5.5 & $1.5-21.1$ \\
railroad worker & 5.6 & $1.2-26.0$ \\
\end{tabular}

${ }^{1}$ ORs controlled for age, sex, ethnic group, ACS division, education, history of diabetes, X-ray treatment, pesticide and herbicide exposure and farming. ${ }^{2}$ For definitions of exposed and not exposed categories, see Tables II, III and IV.-395\% confidence interval. 
causal agents (Piper et al., 1975), the correlation between MM mortality and the poultry industry found at the ecological level (Priester and Mason, 1974), and the suggested role of viruses in human leukemias and lymphomas (Evans, 1982) make plausible the hypothesis of a viral etiology of MM. No information on animal breeding within the farm industry was available in this study, and therefore the viral hypothesis cannot be further investigated.

Possible interpretations of results concerning exposure to pesticides and herbicides (Table VI), in which the separate effect of each group of chemicals could not be distinguished, are that pesticides or herbicides have an effect among farmers only, possibly in relation with higher doses (the median duration of exposure to pesticides or herbicides was 29 years among farmers and 20 years among non-farmers, the difference being not statistically significant), or that other specific chemicals or risk factors related to farming are involved.

However, self-reported exposures to specific chemicals may suffer more easily from recall bias than information derived from occupational history. Exposure to pesticides or herbicides was associated with a higher risk among prevalent cases than among incident cases: this fact suggests caution in the interpretation of findings based on self-reported occupational exposures.

The association between MM and employment as a janitor has been previously reported (Friedman, 1986), as has the association with engine exhausts, possibly related to truck driving (Flodin et al., 1987). Given the small number of exposed cases and controls in these occupations, any interpretation of the present results may be cautious.

Persons employed as cosmetologists (Guidotti et al., 1982; Spinelli et al., 1984; Pearce et al., 1985), in the petroleum industry (Thomas et al., 1980; Decouflé et al., 1983) and in the pulp and wood industry (Milham, 1976; Tollerud et al., 1985; Nandakumar et al., 1986; Flodin et al., 1987) were not at higher risk in the present analysis, since no cases and 4 controls were classified as beautician, cosmetologist or barber, no cases and no controls as oil field or refinery worker, and one case and 8 controls as carpenter, lumber or wood worker. The prevalence of subjects with these occupations in the entire CPSII cohort is very low.

In this analysis, asbestos exposure does not appear to be a risk factor for MM. This result does not seem to be related to control selection, since the proportion of exposed controls closely parallels the overall proportion of exposed subjects in both sexes in CPSII. Asbestos was a risk factor for MM in some (Leiben, 1966; Gerber, 1970; Linet et al., 1987) but not all (Selikoff et al., 1973; Gallagher et al., 1983; Morris et al., 1986) studies that investigated this association. Positive studies reported a 3-fold increase in risk associated with exposure to asbestos. This analysis had a power of about $52 \%$ to detect an $\mathrm{OR}=2$ among incident cases, and a power of about $90 \%$ to detect an OR $=3$.

Occupational exposure to dyes was suggested as a risk factor for MM: the association was present among men only ( 5 cases and 6 controls exposed), and confirms a previously published result (Morris et al., 1986). It is impossible from the present analysis, however, to identify a specific causal agent.

Ionizing radiation is perhaps the best-documented etiologic factor for MM: the strongest evidence comes from studies on mortality of atomic-bomb survivors (Ichimaru et al., 1982) and of radiologists and other occupationally exposed categories (Lewis, 1963; Cuzick, 1981). X-ray therapy was found to be a risk factor for MM in one study (Friedman, 1986), as were "heavy" X-ray examinations (Flodin et al., 1987). One other study (Cuzick and De Stavola, 1988) was substantially negative. Our study did not provide evidence of an effect of X-ray exposure in the clinical setting, and the negative result on occupational exposure to X-rays or radioactive materials $(\mathrm{OR}=1.4, p>0.05)$ must be viewed in the light of the limited power to detect an association (about $56 \%$ to detect an $\mathrm{OR}=2$ ).

Our study suffered from some limitations: diagnoses of cases were based on death certificates only, the self-administered questionnaire gave only limited information on chronic diseases, diet and occupation, namely farming; the small size gave only a limited power to analyze in detail many associations. However, employment as a farmer and previous history of diabetes are the factors that consistently appear to play a role in the etiology of MM in the CPSII cohort. Since few subjects reported these exposures, the population attributable risks to them are low (about $4 \%$ to each factor), and the overwhelming majority of MM cases are likely to have been caused by other factors.

\section{ACKNOWLEDGEMENTS}

We gratefully acknowledge the assistance of Ms. M. Mushinski and Ms. M. Davis in organizing and training researchers and managing the quantities of data; Ms. M.E. Pernas helped in the manual checking of the questionnaires; Dr. D. Lilienfeld and Dr. B. Terracini provided useful comments and advice. We especially thank the 77,000 American Cancer Society volunteers for their role in data collection.

\section{REFERENCES}

Agu, V.U., Christensen, B.L. and Buffler, P.A., Geographic patterns of multiple myeloma: racial and industrial correlates, state of Texas, 1969 71. J. nat. Cancer Inst., 65, 735-738 (1980).

AMERICAN CANCER SOCIETY, Cancer facts and figures-1988. ACS, New York (1988).

Blattner, W.A., Multiple myeloma and macroglobulinemia. In: D. Schottenfeld and J.F. Fraumeni (eds.), Cancer epidemiology and prevention, pp. 795-813, Saunders, Philadelphia (1982).

BlattNer, W.A., Blair, A. and Mason, T.J., Multiple myeloma in the United States, 1950-1975. Cancer, 48, 2547-2554 (1981).

Bourguet, C.C., Grufferman, S., Delzell, E., Delong, E.R. and COHEN, H.J., Multiple myeloma and family history of cancer. A casecontrol study. Cancer, 56, 2133-2139 (1985).

BRESLOW, N.E. and DAY, N.E., Statistical methods in cancer research, Vol. 1, The analysis of case-control studies, IARC Scientific Publication 32, IARC, Lyon (1980).

Brownson, R.C. and REIF, J.S., A cancer registry-based study of occupational risk factor for lymphoma, multiple myeloma and leukemia. Int. J.
Epidemiol., 17, 27-32 (1988).
Bruzzi, P., Green, S.B., Byar, D.P., Brinton, L.A. and Schairer, C., Estimating the population attributable risk for multiple risk factors using case-control data. Amer. J. Epidemiol., 122, 904-914 (1985).

Burmeister, L.F., Everett, G.D., VAN Lier, S.F. and Isacson, P., Selected cancer mortality and farm practices in Iowa. Amer. J. Epidemiol., 118, 72-77 (1983).

CANTOR, K.P. and Blair, A., Farming and mortality from multiple myeloma: a case-control study with the use of death certificates. $J$. nat. Cancer Inst., 72, 251-255 (1984).

Cuzick, J., Radiation induced myelomatosis. N. Engl. J. Med., 304, 204-210 (1981).

Cuzick, J. and De Stavola, B., Multiple myeloma-a case-control study. Brit. J. Cancer, 57, 516-520 (1988).

Decouflé, P., Blattner, W.A. and Blair, A., Mortality among chemical workers exposed to benzene and other agents. Environ. Res., 30, 16-25 (1983).

Delzell, E. and GrufFerman, S., Mortality among white and non-white farmers in North Carolina, 1976-1978. Amer. J. Epidemiol., 121, 391402 (1985).

Devesa, S.S., Silverman, D.T., Young, J.L., Pollack, E.S., Brown, 
C.C., Horm, J.W., Percy, C.L., Myers, M.H., McKay, F.W. and FRAUMENI, J.F., Cancer incidence and mortality trends among whites in the United States, 1947-84. J. nat. Cancer Inst., 79, 701-770 (1987).

Evans, A.S., Viruses. In: D. Schottenfeld and J.F. Fraumeni (eds.), Cancer epidemiology and prevention, pp. 364-390, Saunders, Philadelphia (1982).

Flodin, U., Fredriksson, M. and Persson, B., Multiple myeloma and engine exhausts, fresh wood, and creosote: a case-referent study. Amer. J. indust. Med., 12, 519-529 (1987).

FRIEDMAN, G.D., Multiple myeloma: relation to propoxyphene and other drugs, radiation and occupation. Int. J. Epidemiol., 15, 423-425 (1986). Gallagher, R.P., Spinelli, J.J., Elwood, J.M. and SkipPen, D.H., Allergies and agricultural exposure as risk factors for multiple myeloma. Brit. J. Cancer, 48, 853-857 (1983).

GERBER, M.A., Asbestosis and neoplastic disorders of the hematopoietic system. Amer. J. clin. Path., 53, $204-208$ (1970).

Guidotti, S., Wright, W.E. and Peters, J.M., Multiple myeloma in cosmetologists. Amer. J. indust. Med., 3, 169-171 (1982).

HaKUlinen, T., Isomaki, H. and KNeKT, P., Rheumatoid arthritis and cancer studies based on linking nationwide registries in Finland. Amer. J. Med., 78 (Suppl. 1A), 29-32 (1985).

Ichimaru, M., Ishimaru, T., Mikami, M. and Matsunaga, M., Multiple myeloma among atomic bomb survivors in Hiroshima and Nagasaki, 1950-76: relationship to radiation dose absorbed by marrow. J. nat. Cancer Inst., 69, 323-328 (1982).

IMAHORI, S. and MOORE, G.E. Multiple myeloma and prolonged stimulation of reticuloendothelial system. N.Y. State J. Med., 72, 1625-1628 (1972).

INTERNATIONAL Agency FOR ReSEARCh ON CANCER. IARC Monographs on the evaluation of the carcinogenic risk of chemicals to humans, Suppl. 7, Overall evaluation of carcinogenicity: an update of IARC Monographs Vols. 1-42, IARC, Lyon (1988).

IsOMAKI, H.A., HaKULINEN, T. and JoutsenLAHTI, U., Excess risk of lymphomas, leukemia and myeloma in patients with rheumatoid arthritis. J. chron. Dis., 31, 691-696 (1978).

Johnston, J.M., Grufferman, S., Bourguet, C.C., Delzell, E., DeLONG, E.R. and COHEN, H.J., Socioeconomic status and risk of multiple myeloma. J. Epidemiol. Comm. Hlth, 39, 175-178 (1985).

KYLE, R.A. and GreIPP, P.R., Multiple myeloma. Houses and spouses. Cancer, 51, 735-739 (1983).

LEWIs, E.B., Leukemia, multiple myeloma, and aplastic anemia in American radiologists. Science, 142, 1492-1494 (1963).

LIEBEN, J., Malignancies in asbestos workers. Arch. environ. Hlth, 13, 619-621 (1966)

Linet, M.S., Harlow, S.D. and McLaughlin, J.K., A case-control study of multiple myeloma in whites: chronic antigenic stimulation, occupation, and drug use. Cancer Res., 47, 2978-2981 (1987).

LUBIN, J.H., A computer program for the analysis of matched case-control studies. Comp. biomed. Res., 14, 138-143 (1981).

Mantel, N., Chi-square with one degree of freedom: extension of the Mantel-Haenszel procedure. J. Amer. Statist. Ass., 58, 690-700 (1963).

MANTEL, N. and HAENSZEL, W., Statistical aspects of the analysis of data from retrospective studies of disease. J. nat. Cancer Inst., 22, 719-748 (1959).

McInTYRe, O.R., Myeloma. In: P. Calabresi, P.S. Schein and S.A.
Rosenberg (eds.), Medical oncology, pp. 496-522, Macmillan, New York (1985).

McLaughlin, J.K., Linet, M.S., Stone, B.J., Blot, W.J., Fraumeni, J.F., MaLKer, H.S.R., Weiner, J.A. and ERICSSON, J.L.E., Multiple myeloma and occupation in Sweden. Arch. environ. Hlth, 43, 7-10 (1988).

Miettinen, O., Estimability and estimation in case-referent studies. Amer. J. Epidemiol., 103, 226-235 (1976).

Milham, S., Leukemia and multiple myeloma in farmers. Amer. J. Epidemiol., 94, 307-310 (1971).

Milham, S., Neoplasia in the wood and pulp industry. Ann. N.Y. Acad. Sci., 272, 294-300 (1976).

Morris, P.D., Koepsell, T.D., Daling, J.R., TAYloR, J.W., Lyon, J.L., Swanson, G.M., ChILD, M. and Weiss, N.S., Toxic substance exposure and multiple myeloma: a case-control study. J. nat. Cancer Inst., 76, 987-994 (1986).

Nandakumar, A., Armstrong, B.K. and De Klerk, N.H., Multiple myeloma in Western Australia: a case-control study in relation to occupation, father's occupation, socioeconomic status, and country of birth. Int. J. Cancer, 37, 223-226 (1986).

PearCe, N.E., Smith, A.H. and Fisher, D.O., Malignant lymphoma and multiple myeloma linked with agricultural occupations in a New Zealand cancer registry-based study. Amer. J. Epidemiol., 121, 225-237 (1985).

Petterson, T., Koivunen, E., Ilvonen, M., Jouppila, J., Aalto, E. and WASASTJERNA, C., Sarcoidosis and multiple myeloma: an association. Brit. Med. J., 295, 958 (1987).

PiPer, C.E., AbT, D.A., Ferrer, J.F. and Marshak, R.R., Seroepidemiological evidence for horizontal transmission of bovine C-type virus. Cancer Res., 35, 2714-2716 (1975).

Pottern, L.M. and Blattner, W.A., Etiology and epidemiology of multiple myeloma and related disorders. In: P.H. Wiernik, G.P. Canellos, R.A. Kyle and C.A. Schiffer (eds.), Neoplastic disease of the blood, pp. 413-429, Churchill Livingstone, New York (1985).

PRIESTER, W.A. and MASON, T.J., Human cancer mortality in relation to poultry population, by county, in 10 Southeastern states. J. nat. Cancer Inst., 53, 45-49 (1974).

Selikoff, I.J., Hammond, E.C. and Seidman, H., Cancer risk of insulation workers in the United States. In: P. Bogoski, J.C. Gilson, V. Timbrell and J.C. Wagner (eds.), Biological effects of asbestos, IARC Scientific Publications 8, pp. 209-216, IARC, Lyon (1973).

Sharma, J.M., WitTer, R.L., Burmester, B.R. and Landon, J.C. Public health implications of Marek's disease virus and herpesvirus of turkeys. Studies in human and subhuman primates. J. nat. Cancer Inst. 51, 1123-1128 (1973).

Spinelli, J.J., Gallagher, R.P., Band, P.R. and Threlfall, W.J., Multiple myeloma, leukemia, and cancer of the ovary in cosmetologists and hairdressers. Amer. J. indust. Med., 6, 97-102 (1984).

SteinecK, G. and WiKLUND, K., Multiple myeloma in Swedish agricultural workers. Int. J. Epidemiol., 15, 321-325 (1986).

Thomas, T.L., Decouflé, P. and Moure-Eraso, R., Mortality among workers employed in petroleum refining and petrochemical plants. J. occup. Med., 22, 97-103 (1980).

Tollerud, D.J., Brinton, L.A., Stone, B.J., Tobacman, J.K. and BlatTNER, W.A., Mortality from multiple myeloma among North Carolina furniture workers. J. nat. Cancer Inst., 74, 799-801 (1985).

WoodrofFe, A.J., Multiple myeloma associated with long history of hyposensitisation with allergen vaccines. Lancet, I, 99 (1972). 